UDC: (811.111'276+82):378.147 https://doi.org/10.22190/JTESAP2103551J

Review research paper

\title{
INNOVATIVE PEDAGOGY WITH COMPUTER-SUPPORTED COLLABORATIVE LEARNING IN TEACHING ENGLISH LANGUAGE
}

\author{
Kuldeep Kaur Juneja \\ Nirmala College of Education, Ujjain (M.P.)
}

\begin{abstract}
Today's society is technology motivated and the educational institutions call for new pedagogical ideas. An education process over hauling is needed in all aspects of education like curriculum improvement, teaching learning aspect, assessment, evaluation procedures, etc. One of the basic requirements for education in the future is to prepare learners for participation in a network, information society in which knowledge will be the most critical resource for social and economic development. Computer - Supported Collaborative Learning (CSCL) is one of the most promising innovations to improve teaching and learning with the help of modern Information and Communication Technology (ICT). Research on collaborative learning and the use of information and communication technologies has been integrated in the research area called Computer-Supported Collaborative Learning (CSCL). Collaborative technology refers to specific technological support for collaboration built into computer networks. Such collaborative technology in connection with corresponding pedagogical practices is usually called CSCL environment. Collaborative learning is very important in achieving critical thinking. Individuals are able to achieve higher levels of learning and retain more information when they work in group rather than individually. The knowledge of English has become a prime factor for a nation's development as well as an individual's development. The present paper highlights the distinction made between the collaborative use of technology and collaborative technology for teaching English to undergraduate students.
\end{abstract}

Key words: Information and Communication Technology (ICT), Computer - Supported Collaborative Learning (CSCL), Innovative Pedagogy, Teaching English Language.

\section{INTRODUCTION}

Education is considered to be the driving force for economic and social development in any country. Quality enhancement of education is an important parameter in the assessment and accreditation of any institution. In order to achieve improvement in teaching and learning, innovation helps in rethinking and redesigning of the processes. Information and Communication Technologies (ICT) is an emerging field that plays an important role in augmenting the facilities in teaching and learning progress. ICT in education has made many

Submitted January $15^{\text {th }}, 2021$, accepted for publication March $10^{\text {th }}, 2021$

Corresponding author: Kuldeep Kaur Juneja. Nirmala College of Education, Ujjain (M.P.). Prem Nagar, Dewas Road, Ujjain,456010, India |E-mail: kuldpjuneja@gmail.com 
innovations in the field of teaching which brought a revolutionary change from the old paradigm of teaching and learning to technology enhanced learning. Innovative pedagogy is the study of being an innovative educator or the processes of innovative education teaching. Computer-Supported Collaborative Learning (CSCL) is one of the most promising innovations to improve teaching and learning with the help of modern ICT. According to Lipponen (2001), Collaborative Technology refers to scientific technological support for collaboration built into computer networks. Such collaborative technology in connection with corresponding pedagogical practices is usually called a CSCL environment. Different studies have revealed that CSCL environments can facilitate higher - level cognitive achievements such as critical reasoning, explaining, generating own research questions, setting up and improving one's own intuitive theories, and searching for scientific information.

\section{COMPUTER-SUPPORTED COLLABORATIVE LEARNING}

Lunenberg (1998) believes that value of collaborative learning is in the opportunity for learners to elaborate on their ideas as well as those of their peers. Collaborative Learning is rooted in Lev Vygotsky's concept of learning called zone of proximal development. Typically, there are tasks that learners can and cannot accomplish. Between these two areas is the zone of proximal development, which is a category of things that a leaner can learn but with the help of guidance. The zone of proximal development gives guidance as to what set of skills a learner has that are in the process of maturation. In Vygotsky's definition of zone of proximal development, he highlighted the importance of learning through communications and interactions with others rather than just through independent work. This has made way for the ideas of group learning, one of which is Collaborative Learning. It is very important in achieving critical thinking. Collaborative Learning activities can include collaborative writing, group projects, joint problem solving, debates, study teams, and other activities.

In this sense, collaborative learning offers many possibilities to language teachers, as fluent communication is one of the challenges of collaborative activities. The main advantage of using technology for language learning are a greater exposure to authentic language, access to a wide range of sources of information and to different varieties of language; opportunities for interaction and communication and more intensive learner participation. The activities intend to simulate real - life situations in which students of undergraduate are required to collaborate on projects. Students had to refine their communication skills in English language in order to collaborate successfully in the assignment.

\section{ROLE OF TEACHER}

Structuring collaboration is essential in CSCL environment. Scaffolds as used in Knowledge Forum are an attempt to structure collaboration in CSCL environment. Graphical augmentation tools can support collaboration by providing a shared context for students to discuss. These objects are intended to structure, externalize, and coordinate student's ideas in shared communication. Teacher's role in structuring collaborative learning in teaching drama are:

- One way is to redesign predefined scripts into CSCL environments.

- To motivate students to form groups, to interact and to collaborate and enable them to solve the problem. 
- To engage students to participate equally in collaboration, one can utilize cognitive diversity by making use of interdependency and by giving students different learning materials or by assigning students different roles.

- To integrate individual, cooperative and collaborative activities in script understanding as well as computer - mediated activities.

- To group students taking into consideration language level.

- To give clear, lucid and simple instructions to the group.

- To encourage active participation among the students engaged in collaborative activity.

- To encourage work in close collaboration. The role of teacher is equally important in creating a collaborative learning environment.

\section{ABOUT THIS STUDY}

The significance of teaching English language with ICT has been with us for many years and it continues to grow rapidly with the use of Internet. Since there are more and more English learners in India, different teaching methods have been implemented to test the effectiveness of the teaching process. One method involves Computer-Supported Collaborative Learning in English language teaching in order to create English contexts. The purpose of this study is to develop a Collaborative Learning environment for teaching English language to upper graduate students in Nirmala College, Ujjain. The present study being an experimental study with variables like Computer-Supported Collaborative Learning and ICT. The study involves pre-test and post- test design with treatment in between. Research evidence indicates that Computer-Supported Collaborative Learning and ICT can improve English Language and provide immediate feedback to the learner on his/her progress. Thus, the study assumes its significance and relevance in the above context.

\subsection{Objectives of the Study}

1. To find out the significant difference in achievement mean score between the pretest of control group and the pretest of experimental group.

2. To find out the significant difference in achievement mean score between the post test of control group and the post test of experimental group.

\subsection{Hypothesis}

The following hypotheses were framed for the study:

1. There is no significant difference in achievement mean score between the pre-test of control group and pre-test of experimental group.

2. There is no significant difference in achievement mean score between the post-test of control group and post-test of experimental group.

\subsection{Methodology}

Parallel group experimental method was adopted in the study. The true experimental design employs randomization to groups. The pre-test post-test equivalent groups design was used. 


\subsection{Population and Sample}

The study was confined to 210 upper graduate students of Nirmala College, Ujjain. 105 students were considered as controlled group and another 105 students were considered as a tool for study. The control group was not allowed to get any exposure on the subject matter than the traditional classroom teaching but the experimental group students were given treatment with Computer-Supported Collaborative Learning for teaching English language.

\subsection{Tools}

1. Achievement test in English language constructed and validated by the investigators.

2. The achievement test consisted of objective type questions which carried one mark for each question and contained 20 marks.

\subsection{Statistical technique employed}

The data was collected and analyzed keeping the objectives in view and the design of the study. Descriptive statistics such as Mean and Standard deviation were worked out to describe the nature of data. In order to find the perceived influence of ComputerSupported Collaborative Learning in teaching English language to upper graduate students, t-test was employed. The controlled group was taught by the Lecture method for a week. But the experimental group was taught using Computer-Supported Collaborative Learning environment in improving English language for a week. Thus, the effectiveness of Computer-Supported Collaborative Learning was determined.

\subsection{Data Analysis}

The table below shows the pre-test results of control and experimental group of upper graduate students in teaching English Language.

Table 1 Comparison of the difference between the means of pre-test scores of experimental and control groups of upper graduate students in learning English Language

\begin{tabular}{|l|c|c|c|c|c|}
\hline Groups & $\mathrm{N}$ & $\mathrm{df}$ & Mean & SD & Critical Ratio \\
\hline Control & 105 & \multirow{2}{*}{104} & 8.95 & 1.72 & \multirow{2}{*}{1.90} \\
\cline { 1 - 2 } Experimental & 105 & & 9.29 & 1.85 & \\
\hline
\end{tabular}

The table below shows the post-test scores of control group and experimental group of upper graduate students in teaching English Language.

Table 2 Comparison of the difference between the means of post-test scores of experimental group and control group of upper graduate students in learning English language

\begin{tabular}{|l|c|c|c|c|c|}
\hline Groups & $\mathrm{N}$ & $\mathrm{df}$ & Mean & SD & Critical Ratio \\
\hline Control & 105 & \multirow{2}{*}{104} & 12.73 & 3.93 & \multirow{2}{*}{$7.97^{* *}$} \\
\cline { 1 - 2 } Experimental & 105 & & 16.27 & 2.65 & \\
\hline
\end{tabular}

In pretest, the obtained value of critical ratio for the experimental and control group was 1.90. The obtained value is not significant at .05 level, $(C . R .=1.90, \mathrm{df}=104)$. From 
this it is clear that the students of the two groups do not differ significantly in their initial achievement before experiment. In post - test, the obtained value of critical ratio for the experimental and control groups is 7.97. The obtained value is significant at .01 level, (C.R. $=7.97$, $\mathrm{df}=104)$. From this it is clear that the students of the two groups differ significantly in English Language after experiment. Thus, the hypothesis is rejected.

\section{FINDINGS}

Maria Luisa Cairo Pastor and David Perry (2010) observed that the interdependence and mutual respect among the components of collaborative learning is essential to obtain a coherent proposal. Students and teachers should become a coherent group that dialogues and negotiates in dynamic class. Collaborative language learning is based on the premise that cooperation is more effective for positive learning outcomes. In the opinion of Roschelle and Teasley (1995) collaboration is mutual engagement of participants in a coordinated effort to solve the problem together. The sole aim of the collaboration is to solve problem and that is the whole essence of language and education. Any education that cannot solve problems is not effective. According to Nunan (1993) teachers, learners, researchers, and curriculum specialists can collaborate for purpose of the following:

- Experimentation on alternative ways of organizing teaching and learning.

- Promoting philosophy of cooperation.

- Creating environment in an equitable way for learners and teachers.

- In cooperation of principles of learner centeredness.

\section{INNOVATIVE METHODOLOGIES}

The knowledge of English has become a prime factor for nation's development as well as individual's development.

Visualization - Bring dull academic concepts to life with visual and practical learning experiences. Examples include smart board and internet.

Co-operative Learning - Encourage students of mixed abilities to work together by promoting small group or whole class activities.

Inquiry based - Instruction - Pose thought - provoking questions which inspire your students to think for themselves and become more independent learners.

Technology in the classroom - Incorporating technology into the teaching process is a great way to actively engage the students, especially as digital media surrounds students in the $21^{\text {st }}$ century.

\section{CONCLUSION}

Students in the experimental group had a positive attitude toward CSCL, perceived its utility for helping them learn English Language and had a strong intention to use it in future. Good teaching has always focused on the needs of individual students. The availability of high-quality resources and all kinds of computing devices are making it possible, with teachers to teach their students in such a way that can help them in achieving the greatest success in life. 


\section{SUGGESTIONS}

In face to face interaction, the basic nature of collaborative knowledge construction in the computer- mediated interaction is engaging in the process of constructing and maintaining shared knowledge or understanding it. This is what has been missing when it comes to studying collaboration mediated through computers. Only a few attempts have been made to reveal what goes on between participants in computer -mediated interaction. There is a need to structure student's activities in computer networks through collaborative technology. The fundamental question of what collaborative learning is remains dynamic and guides our choices as researchers, designers, and educators in the field of CSCL.

\section{REFERENCES}

Dixit Uma (2019). ICT - A Pedagogy in Education Process. Quality Teacher Education vis a vis School Education. pp - 285 -289.

Erno Lehtinen, Kai Hakkarainen, Lasse Lipponen, Marjaana Veermens (1999). Computer Supported Collaborative Learning: A Review. The JHGI Giesbers Reports on Education.

Kolluri Elisha (2019). Role of the Collaborative Learning Approach in Teaching Learning Pedagogies. Edutracks. Vol 19, No 1, pp.12-20.

Mukherji Jaya (2005). Higher Education in The Era of Information and Communication Technology - The Teaching and Learning Process. Indian Journal of Educational Research. Vol 24, No 2, pp -31-35.

Maria Luisa Carrio Pastor, Henna Skorczynska (2015). Collaborative Learning and Communication Technologies in Teaching Business English. Procedia - Social and Behavioral Sciences. 178. 32-37. 